\title{
Orthographic, Phonological, and Articulatory Contributions to Masked Letter and Word Priming
}

\author{
Jeffrey S. Bowers \\ Rice University
}

\author{
Gabriella Vigliocco \\ University of Wisconsin-Madison
}

\author{
Richard Haan \\ University of Arizona
}

\begin{abstract}
A series of experiments assessed masked priming for letters and words that are visually similar (SIM) and dissimilar (DIS) in upper- and lowercase formats. For letters, robust DIS priming was obtained in a naming task, but this priming did not extend to a variety of non-naming tasks. For words, robust DIS priming was obtained in both naming and non-naming tasks. SIM letter and word priming extended to all tasks, but the effects were generally small for letters. The restricted set of conditions for DIS letter priming suggests that this priming is mediated by phonological-articulatory processes, and the generality of DIS word priming argues that abstract orthographic codes mediate these effects. Consistent with this conclusion, priming between homophones (for both letters and words) was found in a naming task, but little word homophone priming was obtained in a lexical decision task.
\end{abstract}

According to some theories of reading, readers recognize words "holistically" by matching their overall shape to orthographic representations of complete words. In this view, readers can bypass letter identification and recognize words as complete visual patterns (e.g., Allen, Wallace, \& Weber, 1995). According to most accounts, however, words are recognized via their constituent letters, and the overall shape and transletter features play little or no role in word identification (e.g., Adams, 1979; Besner \& Johnston, 1989; Humphreys, Evett, \& Quinlan, 1990; McClelland \& Rumelhart, 1981). From this perspective, an understanding of the mental representations and processes involved in letter identification is an essential first step for any theory of reading.

Despite the critical role that letter identification plays in most theories of reading, relatively little work has directly assessed the representations and processes involved in letter identification. Instead, researchers typically investigate word (or pseudoword) identification, and the results are assumed to have implications for letters (e.g., Humphreys, Evett, \& Taylor, 1982; McClelland, 1976). Of course, the validity of this inference is only warranted on the assumption that letters and words are equivalent on the dimensions under investigation-an assumption that is rarely assessed. If it turns out that letters and words are represented and processed in different ways, then the results obtained with

Jeffrey S. Bowers, Department of Psychology, Rice University; Gabriella Vigliocco, Department of Psychology, University of Wisconsin-Madison; Richard Haan, Department of Psychology, University of Arizona.

Correspondence concerning this article should be addressed to Jeffrey S. Bowers, who is now at the Department of Experimental Psychology, University of Bristol, 8 Woodland Road, Bristol BS8 1TN, England. Electronic mail may be sent to j.bowers@ bristol.ac.uk. words are uninformative with regard to theories of letter identification.

In the present article, we directly test the letter-word equivalence assumption by comparing masked priming for letters and words in a number of related tasks. Contrary to the common view, we report evidence that qualitatively different mechanisms underlie letter and word primingnamely, phonological-articulatory processes and orthographic representations, respectively.

The masked priming paradigm we used in the present series of experiments includes a number of related tasks that assess the influence of an initial letter or letter string (prime) on the processing of a second letter or letter string (target) when the prime (and in some cases the target) is difficult to identify because of its brief display and the inclusion of premasks and postmasks. For example, in the task introduced by Forster and Davis (1984), a pattern mask (e.g., \#\#\#\#) is replaced by a prime displayed in lowercase letters for $60 \mathrm{~ms}$, which in turn is replaced by a target displayed in uppercase letters for $500 \mathrm{~ms}$. Participants are required to make lexical decisions in response to the targets, and priming is measured as the difference in reaction time between related (e.g., table/TABLE) and unrelated (e.g., flute/TABLE) prime/target pairs. In another task, introduced by Evett and Humphreys (1981), the prime and target are both briefly flashed and masked, and participants are asked to identify the target. Priming, in this latter case, is measured as the difference between the proportions of target identifications when the prime is related to the target and when it is unrelated to the target. ${ }^{1}$

'It is important to emphasize that different processes may mediate masked priming compared with other forms of priming, such as semantic (e.g., Meyer \& Schvaneveldt, 1971) or long-term (e.g., Bowers, 1996) priming. Indeed, there is good evidence that different mechanisms support these various phenomena (e.g., 
Researchers using the priming paradigm often adopt the letter-word equivalence assumption described above. For example, the finding that cross-case word priming is equivalent for prime/target pairs that are visually similar (SIM; e.g., kiss/KISS) and dissimilar (DIS; e.g., read/READ) in their upper- and lowercase formats has led to the view that both words and letters are coded in an abstract format within the orthographic system (Humphreys, Evett, \& Quinlan, 1990; Humphreys et al., 1982). However, adopting this same implicit assumption, Lukatela and Turvey (1994) recently questioned this conclusion on the basis of their observation of a co-occurrence of cross-case and homophone priming. That is, whenever they observed priming between upperand lowercase words (e.g., prime $=S A I L$, target $=$ sail), they also obtained priming between homophones (e.g., prime $=S A L E$, target $=$ sail $)$, which suggests that crosscase and homophone priming are mediated by the same representations - namely, phonological codes. Critical for the present purposes is that Lukatela and Turvey extended this argument, concluded that all reports of cross-case word priming are mediated by phonological codes, and then questioned the need to infer abstract orthographic word and letter codes. Note that in both cases, the authors used priming results obtained with words in order to make claims regarding letter representations: Humphreys et al. claimed that the priming results support the existence of abstract letter codes; Lukatela and Turvey claimed the opposite.

Although most priming studies have included words as target materials, there are a few experiments that have directly assessed priming for single letters (Arguin \& Bub, 1995; Jacobs \& Grainger, 1991; Jacobs, Grainger, \& Ferrand, 1995). Because these studies serve as the starting point for the present investigation, we describe them below in some detail.

Jacobs and Grainger (1991) asked participants to classify target characters as letters or nonletters as quickly as possible. On each experimental trial, an initial mask (\#) was presented for $500 \mathrm{~ms}$, which was replaced by a prime (letter or nonletter) displayed for between 20 and $80 \mathrm{~ms}$, which was replaced by a mask (\#) presented for $16 \mathrm{~ms}$, which in turn was replaced by the target, which remained on the screen until participants responded (e.g., \#a\#A). The critical finding for our purposes was that participants responded faster when the same letter was repeated in lower- and uppercase formats (e.g., $a / A$ ) than when different letters were presented (e.g., $b / A)$-as is the case for words in the lexical decision task. Jacobs and Grainger concluded that abstract orthographic letter codes mediated the priming.

This experiment, however, was recently criticized by Arguin and Bub (1995), who noted that the letters used by Jacobs and Grainger (1991) were not selected in terms of their visual similarity in upper- and lowercase formats in the critical experiment. Some prime/target pairs were SIM (e.g., prime $=c$, target $=C$ ), whereas others were DIS

Forster \& Davis, 1984; Henderson, Wallis, \& Knight, 1984). In this article, the term priming is used descriptively to denote any facilitation in processing a target when it is preceded by a related compared with an unrelated prime. (e.g., prime $=d$, target $=D$ ). Thus, it is possible that the cross-case priming was restricted to the SIM prime/target pairs, in which case the results do not provide evidence for the existence of abstract letter codes. ${ }^{2}$ Indeed, when Arguin and Bub (1995) repeated this experiment using a set of DIS letters in upper- and lowercase formats, they failed to obtain cross-case priming. Similarly, Jacobs et al. (1995) failed to obtain cross-case letter priming using a different baseline condition (i.e., prime intensity) even though they used the same set of letters as did Jacobs and Grainger (1991).

Although Arguin and Bub (1995) failed to obtain crosscase priming for DIS letters using an alphabetic decision task, they did obtain robust priming for these same items when participants were required to name the targets. To rule out the possibility that phonological representations mediated priming in this condition, Arguin and Bub assessed priming between phonologically similar letters (e.g., prime $=p$, target $=b$ ). They reasoned that if phonological representations mediated letter priming in the naming task, then some priming should extend to phonologically similar prime/target pairs. Because they did not find priming in this latter condition, they concluded that the cross-case priming was mediated by abstract orthographic codes.

To account for the contrasting priming results in the alphabetic decision and naming tasks, Arguin and Bub (1995) focused on the different requirements of the two tasks. In considering the alphabetic decision task, they argued that participants performed this task by monitoring the overall level of letter activation within the orthographic system and by responding "letter" when the activation passed some threshold and "nonletter" otherwise. That is, performance on the alphabetic decision task was made in response to some global assessment of letter activation rather than in response to the identification of a specific letter target. Furthermore, they speculated that participants completed the alphabetic decision task by monitoring the global activation of so-called letter tokens, which were defined as visually specific representations of letters that are initially activated during reading and that map onto abstract letter types (e.g., $a$ and $A$ are different letter tokens that map onto the abstract letter type $A$ ). Because performance on the alphabetic decision task is presumed to be mediated by letter tokens (that do not represent the equivalence of upper- and lowercase letters), the absence of cross-case priming in this task is readily explained. By contrast, in the naming task, the overall activation of letter tokens is uninformative with regard to the particular letter name that must be produced. Accurate performance here requires participants to identify the particular letter codes that map onto phonological representations-and these are presumed to be the abstract letter types. Because abstract letter types are relevant to completing the naming task, cross-case letter priming is obtained.

\footnotetext{
${ }^{2}$ Jacobs and Grainger (1991) did in fact assess priming for DIS letters in their Experiment 3, but an inappropriate baseline was used in that study (cf. Arguin \& Bub, 1995). In the critical experiment that included the proper baseline (Experiment 1), SIM and DIS letters were intermixed.
} 
In summary, Arguin and Bub (1995) argued that letter priming is mediated by abstract letter types when participants are required to specifically identify target letters and by visually specific letter tokens when general activation of letter tokens will suffice. Thus, two different types of orthographic codes are assumed to mediate within- and cross-case priming.

The results reported by Arguin and Bub (1995) are important in a number of respects. First, these results provide some evidence compatible with the existence of abstract letter codes which is based on a direct assessment of letter priming (and not inferred from word priming results). Second, the contrasting results obtained with the alphabetic decision and naming tasks highlight the need to include multiple priming tasks before making any conclusions regarding the representations involved in letter identification (see Forster \& Davis, 1991, and Davis \& Forster, 1994, for a similar conclusion regarding word and pseudoword priming). Third, the results demonstrate the importance of selecting letters that are DIS in their upper- and lowercase formats when assessing cross-case priming (see also Bowers, 1996; Bowers, Arguin, \& Bub, 1996).

There are reasons, however, to question Arguin and Bub's (1995) account of letter priming. In particular, we believe that a phonological account of letter priming has not been adequately ruled out. As noted above, Arguin and Bub (1995) rejected a phonological explanation on the basis of their failure to obtain priming between phonologically similar letters. It is important to note, however, that phonological priming may have a narrow generalization gradient, in which case priming would be expected between upperand lowercase letters that share the same name but not between letters with similar names. Indeed, this appears to be the case for words-robust priming was obtained between homophones in a naming task (e.g., Lukatela \& Turvey, 1994) but, in the same task, no priming was obtained between words that rhymed (Forster \& Davis, 1991). Furthermore, it is possible that an articulatory onset effect is responsible for DIS letter priming in the naming task. That is, participants may prepare to articulate the prime prior to the encoding of the target, which in turns facilitates target naming when prime and target share the initial phoneme and inhibits target naming otherwise (see Forster \& Davis, 1991).

We report here a series of six experiments that attempt to shed further light on the representations and processes that support both letter and word priming. In contrast to the account of Arguin and Bub (1995), we provide evidence that phonological-articulatory codes do indeed mediate letter priming. And in contrast to the views of Lukatela and Turvey (1994) and others, we show that orthographic codes support word priming.

\section{Experiment 1}

The goals of this experiment were twofold. First, to test the claim that cross-case letter priming is restricted to SIM items in the alphabetic decision task (Arguin \& Bub, 1995), we assessed cross-case priming for letters that were SIM and
DIS in their upper- and lowercase formats. Second, to determine whether word priming and letter priming are equally sensitive to a case manipulation, we assessed cross-case priming for words that were SIM and DIS in upper- and lowercase formats using a lexical decision task.

\section{Method}

Participants. Twenty-four participants completed the letter priming task, and 24 participants completed the word priming task. Participants were undergraduate students from the University of Arizona and Rice University.

Materials and design: Letters. The target letters consisted of eight letters that were DIS in upper- and lowercase formats and eight letters that were SIM in these formats, as determined through the use of the visual similarity matrix reported by Boles and Clifford (1989). The DIS letters were $A / a, B / b, D / d, E / e, G / g, L /$, $Q / q$, and $R / r$, and the SIM letters were $C / c, K / k, I / t, O / o, P / p, S / s$, $U / u$, and $W / w$. An additional eight nonalphabetic characters were selected to serve as nonletter targets in the alphabetic decision task $(\$,+, \&, ?, \%,=, \hat{,}$, and @).

The letter experiment included prime target relation (primes and targets were repeated vs. primes and targets were nonrepeated) and item type (SIM vs. DIS) as within-subject factors. Each letter was presented in the repeated and nonrepeated conditions three times, which led to 24 trials per condition for a total of 96 letter responses. A corresponding number of nonletter trials were included. In the nonrepeated condition, SIM letters were randomly paired with the other SIM letters and DIS letters were randomly paired with the other DIS letters.

Words. For the word priming experiment, eight DIS and eight SIM words were selected so that they were composed of the corresponding DIS and SIM letters. The DIS words were able, bled, bald, deal, area, edge, gale, and read; the SIM words were cook, chop, kiss, soon, stop, pick, upon, and pump. An additional set of eight SIM and eight DIS random letter strings (e.g., ebqd, $k p s o$ ) were created for the nonword trials in the lexical decision task. The inclusion of random letter strings as the nonword targets ensured that nonwords were easily distinguished from words, which we considered important given that letters were easily distinguished from nonletters in the alphabetic decision task.

The word experiment included prime/target relation (repeated vs. nonrepeated) and item type (SIM vs. DIS) as within-subject factors. Each word was presented in the repeated and nonrepeated conditions three times, which led to 24 trials per condition for a total of 96 word responses. In the nonrepeated condition, SIM words were randomly paired with the other SIM words and DIS words were randomly paired with the other DIS words. A corresponding number of nonword trials were included.

Procedure. In the letter experiment, each trial was organized in the following way. First a pattern mask (\#) was presented for 500 $\mathrm{ms}$, which was replaced by the prime (e.g., a) presented for $50 \mathrm{~ms}$, which was immediately followed by the target (e.g., A), which was displayed for $500 \mathrm{~ms}$. In the word experiment, each trial was organized in the same way except that the mask consisted of four pound signs (\#\#\#). For both experiments, participants completed a set of 18 practice trials prior to the experimental trials. The same set of items was included in the practice and experimental trials, and participants were not informed that the initial trials were practice. In this and all subsequent experiments, stimuli were presented on a computer-controlled video display using the DMASTER system developed by K. I. Forster and J. C. Forster at the University of Arizona. This system synchronizes the display with the video raster so that precise control of stimulus onsets and offsets is possible. 
Participants in the letter and word priming experiments were instructed to press the right shift key as quickly as possible when an uppercase letter or word was displayed and to press the left shift key whenever a nonletter or a nonword was displayed. Participants received feedback on each trial.

\section{Results}

In this experiment, as in subsequent experiments that measured response latencies, the effects of outliers were curtailed by cutoffs established $2 S D$ above and below the mean of each participant. Data from trials on which an error occurred were discarded. Separate analyses of the subject $\left(F_{1}\right)$ and the item $\left(F_{2}\right)$ means were carried out.

Letters. The mean alphabetic decision latencies and error rates in the various conditions are shown in Table 1. An overall analysis of variance (ANOVA) carried out on the reaction time (RT) data failed to reveal a main effect of priming, $F_{1}(1,23)=1.29, M S E=819.53, p>.25$, $F_{2}(1,46)=2.61, M S E=526.82, p=.11$, or an interaction between priming and letter type, $F_{1}(1,23)=1.6, M S E=$ $686.13, p>.2, F_{2}(1,46)=3.09, M S E=526.82, p=.09$, which suggests a failure to obtain priming for both DIS $(0 \mathrm{~ms})$ and SIM (13 ms) letters. However, the SIM priming approached significance, $F_{1}(1,23)=2.6, M S E=829.61$, $p=.12, F_{2}(1,23)=5.36, M S E=558.09, p<.05$. An overall ANOVA carried out on the error scores revealed a main effect of letter type, reflecting a slightly higher error rate for SIM $(6.2 \%)$ than for DIS $(4.4 \%)$ letters, $F_{1}(1,23)=$ 4.64, $M S E=17.11, p<.05, F_{2}(1,46)=4.47, M S E=$ $17.83, p<.05$. No other effect approached significance.

Words. The mean lexical decision latencies and error rates in the various conditions are shown in Table 1. An analysis carried out on the response latencies showed a significant effect of priming, $F_{1}(1,23)=41.66, M S E=$ $215.93, p<.001, F_{2}(1,46)=27.76 . M S E=473.16, p<$ .001 , and no interaction between priming and word type $\left(F_{1}<1, F_{2}<1\right)$, indicating that the same amount of priming was obtained for DIS (25 ms) and SIM (22 ms) words. An analysis on the error scores failed to reveal any significant effects $\left(F_{1}\right.$ values $<3.35, p$ values $>.05 ; F_{2}$ values $<1.77, p$ values $>.15$ ). It should be noted that the average latency for participants to make a "word" response

Table 1

Mean Decision Latencies (in Milliseconds) and Percentage Error Rates as a Function of Item Type in Experiment 1

\begin{tabular}{lccccc}
\hline \multirow{2}{*}{$\begin{array}{c}\text { Prime/target } \\
\text { relation }\end{array}$} & \multicolumn{2}{c}{ DIS letters } & & \multicolumn{2}{c}{ SIM letters } \\
\cline { 2 - 3 } \cline { 5 - 6 } & RT & \% error & & RT & \% error \\
\hline Repeated & 495 & 5.2 & 486 & 6.0 \\
Nonrepeated & 495 & 3.6 & 499 & 6.4 \\
\hline \multicolumn{5}{c}{ Alphabetic decision task } \\
Repeated & 511 & 5.4 & 480 & 4.7 \\
Nonrepeated & 536 & 7.3 & 502 & 5.0 \\
\hline
\end{tabular}

Note. DIS $=$ visually dissimilar; $\mathbf{S I M}=$ visually similar; $\mathrm{RT}=$ reaction time.
(507 ms, collapsing across conditions) is similar to the average latency to make a "letter" response (494 ms, collapsing across conditions). Thus, the contrasting letter and word results do not appear to be related to differences in task difficulty. It is worth pointing out that the inclusion of random letter strings as distractors in the lexical decision task may have reduced the overall size of word priming given that the 24-ms priming effect (collapsing across SIM and DIS words) is much smaller than the typical effect of 50-60 ms (e.g., Forster \& Davis, 1984). Forster (1992) also found that including random-letter-string distractors, as opposed to pseudoword distractors (e.g., blap), reduced priming.

\section{Discussion}

The main results of this experiment can be summarized as follows. For letters, we failed to obtain DIS priming in the alphabetic decision task, consistent with the findings of Arguin and Bub (1995). We also observed a trend for SIM letter priming, which suggests that the cross-case priming reported by Jacobs and Grainger (1991) may have been due to the inclusion of SIM letters in their experiment. For words, we did obtain robust DIS and SIM priming. This DIS word priming is hardly surprising given the many studies that have found cross-case priming for words under similar conditions (e.g., Forster \& Davis, 1984). Nevertheless, the fact that robust priming was obtained for DIS words under experimental conditions that failed to support DIS letter priming makes the null letter results more striking. Thus, it appears that there are interesting differences in the representations or processes responsible for letter and word priming.

\section{Experiment 2}

In this experiment, we attempted to replicate the robust DIS letter priming reported by Arguin and Bub (1995) when the naming task was used.

\section{Method}

Participants. Twenty-four students from the University of Arizona completed the experiment in return for course credit.

Materials and design. The same set of letters used in Experiment 1 was used here. The design was the same except that all nonletter trials were dropped. Accordingly, there were 96 trials, with each letter repeated three times in the repeated and nonrepeated conditions.

Procedure. Each experimental trial consisted of a mask (\#) presented for $500 \mathrm{~ms}$, which was replaced by a lowercase letter displayed for $50 \mathrm{~ms}$ (the prime), which was replaced in turn by an uppercase letter (the target). Target letters remained on the screen for $\mathbf{5 0 0 ~} \mathrm{ms}$ or until participants responded. The participants' task was to name uppercase letters as quickly as possible. The experimenter monitored participants' responses and discarded any trials in which a naming error or a dysfluency occurred.

\section{Results}

The mean naming latencies and error rates in each condition are shown in Table 2 . The overall analysis of the 
Table 2

Mean Naming Latencies (in Milliseconds) and Percentage Error Rates as a Function of Item Type in Experiment 2

\begin{tabular}{lccccc}
\hline \multirow{2}{*}{$\begin{array}{c}\text { Prime/target } \\
\text { relation }\end{array}$} & \multicolumn{2}{c}{ DIS letters } & & \multicolumn{2}{c}{ SIM letters } \\
\cline { 2 - 3 } \cline { 5 - 6 } & RT & \% error & & RT & \% error \\
\hline Repeated & 537 & 0.7 & & 532 & 0.2 \\
Nonrepeated & 558 & 0.9 & & 570 & 2.1 \\
\hline
\end{tabular}

Note. DIS $=$ visually dissimilar; $\mathrm{SIM}=$ visually similar; $\mathrm{RT}=$ reaction time.

naming latencies showed a significant priming effect, $F_{1}(1,23)=33.57, M S E=303.11, p<.001, F_{2}(1,46)=$ $63.58, M S E=328.51, p<.001$, and a significant interaction between priming and letter type, $F_{1}(1,23)=5.55, M S E=$ $303.11, p<.05, F_{2}(1,46)=4.82, M S E=328.51, p<.05$, indicating that a larger amount of priming was obtained for SIM $(38 \mathrm{~ms})$ than for DIS $(21 \mathrm{~ms})$ letters. However, the priming for DIS letters was also significant, $F_{1}(1,23)=$ $22.34, M S E=242.53, p<.001, F_{2}(1,23)=18.33, M S E=$ $299.08, p<.001$. It is worth noting that in Experiment 1 we also found more priming for SIM $(13 \mathrm{~ms})$ than for DIS (0 $\mathrm{ms}$ ) letters. It is possible that the larger amount of SIM priming in the alphabetic decision and naming tasks can be explained in terms of the contribution of perceptual processes common to both tasks that take advantage of the visual similarity of the prime and targets. For example, the advantage of SIM over DIS letters might reflect the contribution of letter tokens that specify the perceptual details of letters, consistent with the account of Arguin and Bub (1995). The basis of the SIM-DIS difference in priming is further considered in the General Discussion.

An analysis of the error data revealed a main effect of priming, $F_{1}(1,23)=4.93, M S E=5.32, p<.05, F_{2}(1$, 46) $=7.29, M S E=3.6, p<.01$, and an interaction of priming with letter type, $F_{1}(1,23)=6.94, M S E=2.62, p<$ $.05, F_{2}(1,46)=5.06, M S E=3.60, p<.01$, reflecting a greater percentage of errors in the nonrepeated $(1.5 \%)$ than in the repeated $(.45 \%)$ condition, particularly for the SIM letters.

\section{Discussion}

The critical finding of the present experiment is that we obtained priming for DIS letters when the naming task was used, consistent with the results of Arguin and Bub (1995). This finding, in combination with the results of Experiment 1 , raises the same question that Arguin and Bub confrontednamely, why is DIS letter priming obtained in some tasks and not in others? According to Arguin and Bub, the naming task requires participants to make an absolute identification for each letter type prior to naming it, whereas the alphabetic decision task only requires participants to monitor the global level of activation of letter tokens. That is, the contrasting priming results reflect the different orthographic codes used in these tasks.

As noted above, however, it is possible that phonological codes or articulatory overlap supported the DIS letter priming when the naming task was used (see Forster \& Davis, 1991, and Lukatela \& Turvey, 1994, for compatible evidence using word targets). Note that the view that letter priming reflects phonological-articulatory processes can readily account for the lack of DIS priming in the alphabetic decision task, because this task does not require participants to phonologically encode or articulate letters.

The next two experiments were designed to test the relative merits of these two explanations. In these experiments we required participants to specifically identify letter and word targets without stressing the naming response. According to Arguin and Bub's (1995) account, DIS letter priming should be obtained in these conditions, whereas according to a phonological-articulatory explanation, no priming should be found.

\section{Experiment 3}

In Experiment 3, participants categorized letter targets as vowels or consonants as quickly as possible. This task required the identification of particular letters, but did not require, at least in principle, access to phonological representations. A corresponding word task was constructed in which participants categorized target words as nouns or verbs as quickly as possible. Again, the absolute identification of the target words was necessary, but phonological encoding was not.

\section{Method}

Participants. Twenty-four students from the University of Arizona completed the letter priming task, and an additional 24 students from Rice University completed the word priming task.

Materials and design. The target letters consisted of four DIS letters, two of which were vowels ( $a$ and $e$ ) and two of which were consonants ( $d$ and $g$ ), as well as four SIM letters, two of which were vowels ( $o$ and $u$ ) and two of which were consonants ( $s$ and $k$ ). Corresponding to these letters, four DIS words were selected, two of which were verbs (earn and tend) and two of which were nouns (gate and tree), as well as four SIM words, two of which were verbs (swim and push) and two of which were nouns (sock and wool).

The letter and word experiments included two within-subject factors: (a) prime/target relation (repeated vs. nonrepeated) and (b) item type (SIM vs. DIS). Each letter and each word were presented in the repeated and nonrepeated conditions six times, which led to 24 trials per condition for a total of 96 word trials and 96 letter trials. For both letters and words, primes and targets in the nonrepeated condition were randomly paired with other items from the same consonant-vowel or noun-verb set. That is, vowels were randomly paired with other vowels (regardless of DIS vs. SIM status), and nouns were randomly paired with nouns (regardless of DIS vs. SIM status). RTs were recorded for all responses.

Procedure. As in the previous experiments, the display included a mask of one or four characters (\# or \#\#\#) presented for $500 \mathrm{~ms}$, followed by the letter or word prime presented in lowercase format for $50 \mathrm{~ms}$, which in turn was replaced by the target item in uppercase format for $500 \mathrm{~ms}$ (e.g., \#-a-A, or \#\#\#\#-earn-EARN).

Participants in the letter categorization experiment were required to press the right shift key as quickly as possible when the target was a vowel and the left shift key when the target was a consonant. Similarly, participants in the word priming experiment pressed the 
right shift key as quickly as possible when the target was a verb and the left shift key when the target was a noun. Eighteen practice trials preceded the experimental trials in both experiments.

\section{Results}

Letters. The categorization latencies and error rates in each condition are shown in Table 3 . No main effect of priming for RTs was obtained, $F_{1}(1,23)=2.33, M S E=$ $318.85, p=.14, F_{2}(1,46)=1.46, M S E=755.32, p=.23$, and the interaction between priming and letter type did not approach significance $\left(F_{1}<1\right.$ and $\left.F_{2}<1\right)$. Nevertheless, a simple contrast revealed a slight trend for SIM letter priming $(9 \mathrm{~ms}), F_{1}(1,23)=1.98, M S E=508.90, p=.17, F_{2}(1$, $23)=1.85, M S E=465.13, p=.19$. The ANOVA carried out on the error data revealed a main effect of letter type, $F_{1}(1,23)=4.88, M S E=18.03, p<.05, F_{2}(1,46)=5.27$, $M S E=16.54, p<.05$, reflecting the higher proportion of errors with DIS $(4.7 \%)$ than with SIM (2.8\%) letters. No other effect achieved significance.

Words. The categorization latencies and error rates in each condition are shown in Table 3. An overall ANOVA carried out on the RTs revealed a main effect of priming, $F_{1}(1,23)=17.48, M S E=2,068.84, p<.001, F_{2}(1,46)=$ $29.79, M S E=1,153.22, p<.001$, and no interaction between priming and word type $\left(F_{1}\right.$ and $\left.F_{2}<1\right)$, reflecting the equivalent priming for DIS (34 ms) and SIM (34 ms) words. The analysis of the errors did not reveal any significant effects (all $F_{1}$ values $<2.28$, all $p$ values $>.13$; all $F_{2}$ values $<1.83$, all $p$ values $>.18$ ).

\section{Discussion}

The critical finding in Experiment 3 is that no priming was obtained for DIS letters in a categorization task that required participants to make absolute identifications of target letters. This result contrasts with the robust letter priming in the naming task reported in Experiment 2. Thus, priming for DIS letters does not depend on whether participants specifically identify the target letters, contrary to the conclusion of Arguin and Bub (1995). The SIM letter priming was nonsignificant, but there was a small trend for priming,

Table 3

Mean Categorization Latencies (in Milliseconds) and Percentage Error Rates as a Function of Item Type in Experiment 3

\begin{tabular}{|c|c|c|c|c|}
\hline \multirow{2}{*}{$\begin{array}{l}\text { Prime/target } \\
\text { relation }\end{array}$} & \multicolumn{2}{|c|}{ DIS letters } & \multicolumn{2}{|c|}{ SIM letters } \\
\hline & RT & $\%$ error & $\overline{\mathrm{RT}}$ & $\%$ error \\
\hline \multicolumn{5}{|c|}{ Vowel-consonant categorization } \\
\hline Repeated & 519 & 3.83 & 509 & 3.30 \\
\hline Nonrepeated & 522 & 5.56 & 518 & 2.26 \\
\hline \multicolumn{5}{|c|}{ Noun-verb categorization } \\
\hline Repeated & 673 & 3.3 & 634 & 3.7 \\
\hline Nonrepeated & 707 & 3.8 & 668 & 2.1 \\
\hline
\end{tabular}

Note. DIS = visually dissimilar; SIM $=$ visually similar; $\mathrm{RT}=$ reaction time. consistent with the prior results. A second important finding is that robust word priming was obtained in a noun-verb categorization task, and this priming was equal in size for both DIS and SIM words. These results parallel the lexical decision results reported in Experiment 1.

\section{Experiment 4}

To provide additional support for the claim that DIS letter priming is restricted to tasks that emphasize phonologicalarticulatory processes, we assessed letter priming in a perceptual identification task. The challenge for participants was to identify specific target letters under degraded perceptual conditions, and thus we reasoned that orthographic processes are stressed to a greater extent in this task than in the naming task, in which items are presented in the clear. Thus, according to the phonological-articulatory account, DIS letter priming should be minimal. A parallel task with words was also conducted. If orthographic codes support word priming, DIS word priming should be robust.

\section{Method}

Participants. Twenty-four students from Rice University completed the letter identification task, and another group of 26 students from the same participant pool completed the word identification task.

Materials and design. Seven DIS letters $(a, b, d, e, g, q$, and $r)$ and seven SIM letters ( $c, k, o, s, u, w$, and $z)$ were included in the letter experiment. In the word priming task, 56 DIS words and 56 SIM words were included. All were four letters in length. Half of the words were low in frequency (median frequency $=4$, range $=1-17$ occurrences per million), and half of the words were high in frequency (median frequency $=123$, range $=15-1,303$ occurrences per million; Kuçera \& Francis, 1967). All DIS and SIM words were composed of at least three DIS or SIM letters, respectively.

In both experiments there were two within-subject factors: (a) prime/target relation (repeated vs. nonrepeated) and (b) item type (SIM vs. DIS). In the letter experiment, each letter was presented four times in the repeated condition and four times in the nonrepeated condition, which led to 112 trials. SIM letters were randomly paired with other SIM letters, and DIS letters were randomly paired with other DIS letters in the nonrepeated condition. In the word experiment, words were not repeated, which prevented participants from guessing the target on the basis of preceding exposures to the same item. ${ }^{3}$ Two versions of the test were created so that each word was presented in the repeated and the nonrepeated conditions, creating a fully counterbalanced design. Thus, each participant completed 112 experimental word trials. In the nonrepeated condition, SIM words were randomly

\footnotetext{
${ }^{3}$ Given that there was no time pressure to respond in the identification task, we reasoned that guessing might be a problem if a small set of words from the large set of possible words was repeated multiple times. Note that this was not as much of a problem for the letter experiment, where more than half of the possible items were repeatedly presented, which rendered guessing from past trials less informative. Nor was this a problem in the other word priming tasks because participants were required to respond quickly.
} 
paired with other SIM words, and DIS words were randomly paired with other DIS words.

Procedure. Each experimental trial consisted of a mask (\# or \#\#\#) presented for $500 \mathrm{~ms}$, which was replaced by a lowercase letter or word prime, which was replaced in turn by the target letter or word in uppercase format, which was finally replaced by another mask (\# or \#\#\#) for $500 \mathrm{~ms}$. To equate the performance as closely as possible for the two materials, we displayed prime and target letters for $34 \mathrm{~ms}$ each, whereas prime and target words were displayed for $17 \mathrm{~ms}$ each. ${ }^{4}$ Participants were asked to identify any letter or word that they saw, and they were encouraged to guess. Responses were considered correct if participants identified either the prime or the target, which provides a conservative test of priming given that two possible responses are correct in the baseline condition and only one response is correct in the repeated condition. We adopted this criterion because it is rather arbitrary to consider the identification of one item correct and the identification of the other item as incorrect under conditions in which the prime and target are presented for the same duration.

\section{Results}

Letters. The identification rate in each condition is shown in Table 4. As can be seen in this table, robust letter priming was obtained for SIM letters (20\% improvement), and relatively little priming was obtained for DIS letters (5\% improvement). An overall ANOVA revealed a significant effect of priming, $F_{1}(1,25)=49.30, M S E=.01, p<.001$, $F_{2}(1,54)=18.01, M S E=0.03, p<.001$, and an interaction between priming and letter type, $F_{1}(1,25)=11.92, M S E=$ $0.01, p<.01, F_{2}(1,54)=6.12, M S E=0.03, p<.05$, reflecting the greater amount of priming for SIM than for DIS letters. A simple contrast failed to reveal priming for DIS letters, although the effect approached significance, $F_{1}(1,25)=3.05, M S E=0.03, p=.09, F_{2}(1,27)=1.87$, $M S E=0.04, p=.19$.

Words. The identification rate in each condition is shown in Table 4. An ANOVA carried out on these data revealed a priming effect, $F_{1}(1,22)=112.07, M S E=0.06$, $p<.001, F_{2}(1,52)=291.99, M S E=0.03, p<.001$, and

Table 4

Probability of Letter Identification as a Function of Item Type and Probability of Word Identification as a Function of Item Type and Word Frequency in Experiment 4

\begin{tabular}{ccc}
\hline $\begin{array}{c}\text { Prime/target } \\
\text { relation and } \\
\text { word frequency }\end{array}$ & DIS letters & SIM letters \\
\hline & Letter identification \\
Repeated & .49 & .71 \\
Nonrepeated & .44 & .51 \\
\hline & Word identification & \\
High frequency & & .72 \\
Repeated & .68 & .26 \\
Nonrepeated & .31 & .64 \\
Low frequency & & .24 \\
Repeated & .47 & .17 \\
Nonrepeated & .7 & \\
\hline
\end{tabular}

Note. DIS = visually dissimilar; SIM = visually similar. the interaction between priming and word type approached significance, $F_{1}(1,22)=7.03, M S E=0.02, p<.05, F_{2}(1$, $52)=2.52, M S E=0.04, p=.12$, reflecting the greater amount of priming for SIM words (.43) than for DIS words (.34). In addition, the interaction between priming and word frequency approached significance, $F_{1}(1,22)=2.46$, $M S E=0.20, p=.13, F_{2}(1,52)=3.27, M S E=0.03, p=$ .08 , reflecting a tendency to show more priming for high(.42) than for low-frequency (.35) words.

\section{Discussion}

The critical finding of Experiment 4 is that robust priming was obtained for DIS words but that only a nonsignificant trend was obtained for DIS letters under similar test conditions. These results closely match the results of Experiment 3 , in which a categorization task was used, and thus they further challenge the view according to which priming is obtained for DIS letters as long as participants identify specific letters. Instead, the results are consistent with the view that letter priming is restricted to tasks that emphasize phonological-articulatory processes-that is, the naming task. Note that even the small trend for DIS letter priming in the identification task may be mediated by phonological codes given the past finding that phonological codes contribute to priming in the identification task in some circumstances (e.g., Humphreys et al., 1982; Perfetti \& Bell, 1991; Perfetti, Bell, \& Delaney, 1988; see Verstaen, Humphreys, Olson, \& D'Y dewalle, 1996, for evidence that phonological priming is the product of strategic rather than automatic processes).

Finally, it is worth noting that we found more priming for SIM than for DIS words, in contrast to the results of previous experiments in which we found similar amounts of priming for each. A related finding was reported in the literature by Davis and Forster (1994), who found that word priming was only influenced by the perceptual overlap of the prime and target when both items were presented briefly. (The perceptual overlap had no effect when the targets were presented in free view.) Thus, it appears that visually specific perceptual codes play a larger role in priming when targets are presented briefly. Note that this may also explain why SIM letter priming was larger in the present identification task than in the previous tasks in which letter targets were presented for $500 \mathrm{~ms}$.

\section{Experiment 5}

The previous experiments provide a clear-cut picture regarding the conditions in which DIS letter priming and word priming are obtained. That is, robust DIS letter priming was restricted to the naming task, whereas robust DIS word priming was obtained in all the tests we used: namely, lexical decision, naming, noun-verb categorization, and

\footnotetext{
${ }^{4}$ When prime/target words and letters were presented for $34 \mathrm{~ms}$ in a pilot experiment, participants identified many more words than letters in the baseline conditions, presumably because of the word superiority effect (Reicher, 1969).
} 
perceptual identification tasks. These contrasting findings are all the more striking given that the letter and word tasks were closely matched. Thus, the present set of results suggests that qualitatively different representations or processes mediate priming for letters and words.

One hypothesis that can readily account for this pattern of results is that phonological-articulatory processes mediate DIS letter priming, whereas abstract orthographic codes mediate DIS word priming. However, before this hypothesis can be strongly endorsed, it is important to provide independent evidence in support of this position. We carried out the final two experiments in an attempt to provide this evidence. In Experiment 5, we assessed priming between word homophones in a naming task and a lexical decision task. If word priming is largely supported by abstract orthographic codes in the lexical decision task and by phonologicalarticulatory codes in the naming task, then homophone priming should be more robust in the latter task.

\section{Method}

Participants. Twenty-four students from the University of Arizona completed the naming task, and 24 students from Rice University completed the lexical decision task.

Materials and design. The set of homophone pairs included in Appendix A of Lukatela and Turvey's (1994) study was used in the present experiment. One member of each pair served as the prime, the other as the target. This list was divided into two sets: In half the pairs, the prime was higher in frequency than the target (mean frequencies of the prime and target were 173 and 12 occurrences per million, respectively; Kuçera \& Francis, 1967), and in half the pairs, the target was higher in frequency than the prime (mean frequencies of the prime and target were 18 and 97 occurrences per million, respectively). The members of the homophone pairs that served as primes and targets in the present experiment were slightly different than those in the Lukatela and Turvey (1994) study because we required targets to be composed of either the same number of letters as or more letters than the prime. This ensured that targets served as adequate masks for primes. In the baseline condition, we included the same set of control words as did Lukatela and Turvey; these were matched with the targets so that (a) they had no letters in common (or in rare cases, just one letter, but in a different position), (b) they had the same number of letters, (c) they were approximately the same frequency, and (d) they were not prominent associates of their corresponding targets. An additional 96 pronounceable nonword targets were constructed that were matched with word targets in terms of number of letters. All the nonwords were one letter different from real words, and no pseudohomophones were included. Nonword targets were presented in uppercase letters and were only used in the lexical decision experiment.

The experiment included three conditions: a condition in which the prime and target were repeated (e.g., prime $=$ sail, target $=S A(L)$, a condition in which the prime and target were homophones (e.g., prime $=$ sale, target $=S A I L$ ), and a condition in which the prime was unrelated to the target (e.g., prime $=$ butt, target $=S A l L)$. Three lists were constructed so that each homophone target was presented in the three conditions equally often, producing a counterbalanced design. Consistent with the earlier studies, primes were presented in lowercase letters, and targets in uppercase letters. This presentation contrasts with that in the Lukatela and Turvey (1994) study, in which the primes were presented in uppercase letters and the targets in lowercase letters.
Procedure. Experimental trials in both the naming and lexical decision tasks consisted of a mask composed of eight pound signs (\#\#\#\#\#\#) presented for $500 \mathrm{~ms}$, which was replaced by the lowercase prime displayed for $50 \mathrm{~ms}$, which was replaced in turn by the target word in uppercase letters. Target words remained on the screen for $500 \mathrm{~ms}$ or until participants responded. Participants in the naming task were asked to name the target word as quickly as possible. The experimenter monitored participants' responses and discanded any trials in which a naming error or a dysfluency occurred. Participants in the lexical decision task were required to press the right shift key as quickly as possible when words were presented and the left shift key when nonwords were presented.

\section{Results}

Naming. The mean naming latencies and error rates in each condition are shown in Table 5. As can be seen in this table, the priming effects for RTs generally conform to the findings reported by Lukatela and Turvey (1994): Robust repetition priming $(40 \mathrm{~ms})$ and homophone priming $(28 \mathrm{~ms})$ were obtained. An overall ANOVA carried out on the RT data revealed a main effect of priming, $F_{1}(2,42)=22.73$, $M S E=860.50, p<.001, F_{2}(2,180)=49.71, M S E=$ $836.33, p<.001$, and no interaction between the prime/ target relative frequencies and the effect of priming, $F_{2}(2,42)=1.08, M S E=695.99, p=.35, F_{2}(2,180)=$ $1.86, M S E=836.33, p=.16$. An analysis of the error scores also revealed a main effect of priming, $F_{1}(2,42)=11.32$, $M S E=14.03, p<.01, F_{2}(2,180)=8.73, M S E=36.53$, $p<.01$, reflecting the greater percentage of errors in the nonrepeated condition $(5.1 \%)$ than in the repeated $(2.21 \%)$ and homophone $(1.69 \%)$ conditions. In addition, the interaction between priming and the prime/target relative frequen-

\section{Table 5}

Mean Latencies (in Milliseconds) and Percentage Error Rates as a Function of Prime/Target Relative Frequencies in Experiment 5

\begin{tabular}{ccc}
\hline $\begin{array}{c}\text { Prime/target } \\
\text { frequencies and } \\
\text { prime/target } \\
\text { relation }\end{array}$ & Reaction time & \% error \\
\hline Nigh/low & Naming task & \\
Repeated & 492 & 1.6 \\
Homophone & 504 & 2.1 \\
Nonrepeated & 525 & 6.8 \\
Low/high & & \\
Repeated & 474 & 2.9 \\
Homophone & 487 & 1.3 \\
Nonrepeated & 520 & 3.3 \\
\hline & Lexical decision task & \\
High/low & & 11.7 \\
Repeated & 562 & 14.0 \\
Homophone & 591 & 15.7 \\
Nonrepeated & 608 & 2.8 \\
Low/high & & 6.0 \\
Repeated & 537 & 8.3 \\
Homophone & 574 & \\
Nonrepeated & 570 & \\
\hline
\end{tabular}


cies was significant, $F_{1}(2,42)=3.55, M S E=18.56, p<$ $.05, F_{2}(2,180)=3.62, M S E=36.53, p<.05$, reflecting the high percentage of errors in the high/low frequency condition for nonrepeated words $(6.8 \%)$.

To distinguish between repetition and homophone priming, we carried out two separate ANOVAs on the RT data. The ANOVA assessing repetition priming revealed a main effect of priming, $F_{1}(1,21)=33.67, M S E=1,105.21, p<$ $.001, F_{2}(1,90)=75.35, M S E=1,051.88, p<.001$, and the interaction between repetition priming and the relative frequencies of items also approached significance, $F_{1}(1,21)=2.88, M S E=430.19, p=.11, F_{2}(1,90)=2.35$, $M S E=1,051.88, p=.13$, reflecting a trend for more priming in the high/low $(46 \mathrm{~ms})$ than the low/high $(33 \mathrm{~ms})$ frequency condition. The ANOVA assessing homophone priming also showed an overall priming effect, $F_{1}(1,21)=$ $27.39, M S E=657.55, p<.001, F_{2}(1,90)=46.76, M S E=$ $811.36, p<.001$, and the interaction between homophone priming and relative frequencies of items approached significance, $F_{1}(1,21)=1.25, M S E=295.53, p=.28 ; F_{2}(1$, $90)=2.69, M S E=811.36, p=.11$, reflecting a trend for more homophone priming in the low/high $(33 \mathrm{~ms})$ than the high/low (21 ms) frequency condition.

Lexical decision. The mean lexical decision latencies and error rates in each condition are shown in Table 5. In sharp contrast to the results obtained with the naming task, priming was largely restricted to the repetition condition (39 $\mathrm{ms})$, with little priming for homophones $(6 \mathrm{~ms})$. An overall ANOVA carried out on the RT data revealed a significant amount of priming, $F_{1}(2,42)=30.71, M S E=686.84, p<$ $.001, F_{2}(2,180)=13.26, M S E=3,019.52, p<.001$, and the interaction between priming and the prime/target relative frequencies approached significance, $F_{1}(2,42)=2.33$, $M S E=624.80, p=.11, F_{2}(2,180)=1.44, M S E=$ $4,278.82, p=.24$. An analysis on the error scores revealed a main effect of priming, $F_{1}(2,42)=6.66, M S E=42.11, p<$ $.01, F_{2}(2,180)=5.77, M S E=97.11, p<.01$, reflecting the smaller percentage of errors in the repeated $(7.3 \%)$ condition than in the homophone $(10.0 \%)$ and nonrepeated $(12.1 \%)$ conditions, as well as an effect of the prime/target relative frequencies, $F_{1}(1,21)=45.97, M S E=52.05, p<.01$, $F_{2}(1,90)=12.26, M S E=391.06, p<.01$.

To distinguish repetition from homophone priming, we carried out two separate ANOVAs on the RT data. The ANOVA that assessed repetition priming revealed a main effect of priming, $F_{1}(1,21)=41.31, M S E=887.44, p<$ $.001, F_{2}(1,90)=23.76, M S E=2,747.52, p<.001$, and no interaction between repetition priming and the prime/target relative frequencies, $F_{1}(1,21)=2.80, M S E=326.30, p=$ $.11, F_{2}(1,90)<1$, reflecting the similar amounts of priming in the high/low (46 ms) and low/high $(33 \mathrm{~ms})$ frequency conditions. By contrast, the ANOVA assessing homophone priming failed to show an overall priming effect, $F_{1}(1,21)=$ $1.69, M S E=582.56, p=.21, F_{2}(1,90)<1$, although the interaction between homophone priming and the relative frequencies of items did approach significance, $F_{1}(1,21)=$ $3.61, M S E=802.15, p=.07, F_{2}(1,90)=2.74, M S E=$ $3,156.94, p=.10$, suggesting that homophone priming was in fact obtained in the high/low (17 ms) but not in the low/high ( $-4 \mathrm{~ms})$ frequency condition.

\section{Discussion}

Two main results were obtained in Experiment 5. First, and consistent with the findings of Lukatela and Turvey (1994), we obtained robust homophone priming in the naming task. On the basis of these and related findings (e.g., Forster \& Davis, 1991), it seems clear that phonologicalarticulatory processes do indeed support priming for words when the naming task is used. Second, when the lexical decision task was used, priming for the same set of homophones was severely reduced. This latter finding suggests that phonological-articulatory processes do not play as large a role in mediating priming when target items are not named.

Although the homophone priming was reduced in the lexical decision task, we did observe a small amount of priming when the target homophones were lower in frequency than the primes. This finding closely parallels one in a recent study by Grainger and Ferrand (1994), who also found minimal overall priming for homophones $(5 \mathrm{~ms})$ in the lexical decision task but obtained more homophone priming when primes were higher in frequency than targets ( $24 \mathrm{~ms}$ ) as opposed to when primes were lower in frequency $(-14 \mathrm{~ms}$; Experiment 1$)$. It is also interesting to note that Grainger and Ferrand (1994) failed to obtain priming for low-frequency homophone targets in the lexical decision task when pseudohomophones were included in the set of nonword foils (Experiment 2), which provides a further restriction on the conditions in which homophone priming is obtained. Additional studies, however, have reported priming between pseudohomophones and word targets, such as mayd-MADE (Ferrand \& Grainger, 1992, 1993, 1994), regardless of the target frequency. Thus, properties of the prime may also be relevant to whether or not phonological priming is obtained in the lexical decision task. However, even in these latter experiments, there was evidence that orthographic representations contributed to the priming results.

The general conclusion that we draw from these and related findings is that the role of phonology in word priming depends on many factors, including the type of task (e.g., lexical decision vs. naming; e.g., Forster \& Davis, 1991), the materials (e.g., high- vs. low-frequency words; e.g., Grainger \& Ferrand, 1994), and the environment in which words are tested (e.g., the inclusion vs. exclusion of pseudohomophones in a lexical decision task; e.g., Davelaar, Coltheart, Besner, \& Jonasson, 1978). Note that the influence of these factors on priming presumably reflects their more general influence on word identification.

These findings have clear implications for the DIS word priming results reported earlier. Given that the DIS words were predominantly high in frequency, and given the large size of the DIS priming in the various tasks (much larger than any homophone priming effect we observed), we argue that the robust DIS word priming was largely mediated by abstract orthographic codes. The implication of these results 
for the DIS letter priming results is less straightforward, but given that homophone priming and DIS letter priming are largely restricted to the naming tasks, it appears that phonological-articulatory processes support both forms of priming. However, to avoid the fallacy of generalizing from words to letters, it is important that we directly assess the role of phonological processes in supporting DIS letter priming. This was the purpose of Experiment 6.

\section{Experiment 6}

In this last experiment, we assessed homophone priming using letter targets. One difficulty in setting up such an experiment is that different letters never share the same name. Therefore, we assessed priming between homophone word/letter pairs, such as sea/C, as well as between repetitions (e.g., $c / C$ ). If homophone priming and repetition priming are equivalent, the findings would support the conclusion that letter priming is mediated entirely by phonological-articulatory processes. In addition, we assessed priming between phonologically similar letters (e.g., $z / C$ ) in an attempt to replicate Arguin and Bub's (1995) failure to obtain priming between such items. A combination of robust priming for homophones and little or no priming between phonologically similar letters would suggest that phonological-articulatory letter priming has a narrow generalization gradient, consistent with word priming results (Forster \& Davis, 1991). ${ }^{5}$

\section{Method}

Participants. Sixteen students from the University of Wisconsin-Madison completed the letter priming task in return for course credit.

Materials and design: Letters. The target letters consisted of $C, Q, Y$, and $R$, which are homophonous with the word primes sea, cue, why, and are, respectively. The letters $z, k, i$, and $a$ served as phonologically similar primes to the targets, respectively.

The experiment included prime/target relation as a withinsubject factor (repeated vs. homophonous vs. phonologically similar vs. nonrepeated). Different baselines were used to assess homophone priming on the one hand, and phonologically similar and repetition priming on the other. The nonrepeated condition for the homophones consisted of a random pairing of one of the word primes with the letter targets (e.g., sea/Q), whereas for the latter conditions it consisted of a random pairing of one of the letter primes with the targets (e.g., $z / Q$ ). Each target letter was presented five times in each condition, which led to 20 trials per condition for a total of 100 trials. The 100 trials were presented in a random order.

Procedure. Each trial was organized in the following way. First a pattern mask (\#*\#) was presented for $500 \mathrm{~ms}$, which was replaced by the prime for $50 \mathrm{~ms}$. The prime was immediately followed by the same pattern mask (\#*\#) for $33 \mathrm{~ms}$, which was immediately followed by the target, which was displayed for $500 \mathrm{~ms}$. The second mask was included in order to mask the first and last letters of the word primes prior to the presentation of the targets given that these word primes were longer than the letter targets. This particular pattern mask was included because it effectively masked the word primes. Participants completed a set of 18 practice trials prior to the experimental trials. The same set of items was included
Table 6

Mean Naming Latencies (in Milliseconds) and Percentage Error Rates as a Function of Prime/Target Relation in Experiment 6

\begin{tabular}{lcc}
\hline \multicolumn{1}{c}{ Prime/target relation } & $\begin{array}{c}\text { Reaction } \\
\text { time }\end{array}$ & \% error \\
\hline Homophone & 517 & .6 \\
Homophone baseline & 537 & 1.6 \\
Repetition & 514 & .9 \\
Phonologically similar & 531 & .0 \\
Repetition and similar baseline & 536 & 1.3 \\
\hline
\end{tabular}

in the practice and experimental trials, and participants were not informed that the initial trials were practice.

Participants were asked to name the target words as quickly as possible. The experimenter monitored participants' responses and discarded any trials in which a naming error or a dysfluency occurred.

\section{Results}

The naming latencies in each condition are shown in Table 6. As can be seen in this table, robust repetition priming ( $21 \mathrm{~ms}$ ) and homophone priming were obtained (20 $\mathrm{ms}$ ), and little priming was obtained between phonologically similar letters $(5 \mathrm{~ms})$. An overall ANOVA carried out on the RT data revealed a significant effect of priming, $F_{1}(4,60)=$ $7.98, M S E=229.19, p<.01, F_{2}(4,76)=8.59, M S E=$ $255.45, p<.01$, and the small priming effect obtained between phonologically similar letters $(5 \mathrm{~ms})$ did not achieve significance, $F_{1}(1,15)=1.42, p>.1, F_{2}(1$, $19)<1$. An analysis carried out on the error results failed to reveal any significant effects, $F_{1}(4,60)=1.42, p>.2$, $F_{2}(4,76)=1.52, p>.2$.

One possible explanation for the homophone priming results that would not implicate phonological processes is that two of the prime words shared a letter with the target ( $w h y / Y$ and are/R). If priming was restricted to these items, it could be argued that the priming was mediated by the abstract letter codes common to these primes and targets. This possibility seems unlikely given the significant priming results on the item analysis, but in order to check this possibility directly, we examined the priming effects obtained with the $C$ and $Q$ targets and the $Y$ and $R$ targets separately. The $Y$ and $R$ priming was similar in the homophone (26 ms) and repetition ( $24 \mathrm{~ms})$ conditions, as was the case for the $C$ and $Q$ priming in the homophone $(13 \mathrm{~ms})$ and repetition $(18 \mathrm{~ms})$ conditions. In addition, phonologically similar letter priming was reduced for both the $Y$ and $R$ ( 8 $\mathrm{ms})$ and the $C$ and $Q(1 \mathrm{~ms})$ items. An analysis of these data was selectively carried out on the $C$ and $Q$ condition, in which the prime words and the targets shared no letters. Once again, significant priming was found for RTs, $F_{1}(4,60)=2.84, M S E=419.10, p<.05$, and critically, a simple contrast revealed significant homophone priming,

\footnotetext{
${ }^{5}$ We would like to thank Martin Arguin and Derek Besner for helpful discussion that led to the development of this experiment.
} 
Table 7

Summary of the Main Priming Effects (Repeated-Nonrepeated) in Experiments 1-4

\begin{tabular}{|c|c|c|c|c|}
\hline Experiment and task & $\begin{array}{l}\text { SIM letter } \\
\text { priming }\end{array}$ & $\begin{array}{l}\text { DIS letter } \\
\text { priming }\end{array}$ & $\begin{array}{l}\text { SIM word } \\
\text { priming }\end{array}$ & $\begin{array}{l}\text { DIS word } \\
\text { priming }\end{array}$ \\
\hline $\begin{array}{l}\text { Experiment 1: Alphabetic and lexical decision tasks } \\
\text { (effect in } \mathrm{ms} \text { ) }\end{array}$ & $13 *$ & 0 & $22 * *$ & $25^{* *}$ \\
\hline Experiment 2: Letter naming (effect in ms) & $38 * *$ & $21 * *$ & 2 & - \\
\hline $\begin{array}{l}\text { Experiment 3: Vowel-consonant and noun-verb } \\
\text { decision tasks (effect in ms) }\end{array}$ & 9 & 3 & $34 * *$ & $34 * *$ \\
\hline Experiment 4: Perceptual identification (effect in \%) & $20^{* *}$ & 5 & $43^{* *}$ & $34 * *$ \\
\hline
\end{tabular}

Note. $\quad$ SIM $=$ visually similar; DIS $=$ visually dissimilar.

${ }^{*} p<.05$, item analysis only. ${ }^{* *} p<.05$, item analysis and subject analysis.

$F_{1}(1,15)=5.67, M S E=254, p<.05$. Accordingly, the significant homophone priming must be attributed to phonological-articulatory processes.

\section{Discussion}

Consistent with the word results of Experiment 5, robust homophone priming was obtained for letter targets in the naming task. Indeed, the homophone priming was equal in magnitude to the repetition priming, which suggests that all of the priming was mediated by phonological-articulatory codes. Thus, this last experiment provides direct evidence for our characterization of DIS letter priming without making inferences from word data. In addition, our failure to obtain priming between phonologically similar letters (a) indicates that phonological-articulatory priming is highly specific and (b) suggests that priming is only obtained when letters share the same name or when words share the same name or onset (e.g., Forster \& Davis, 1991). ${ }^{6}$

\section{General Discussion}

Three main sets of results are reported in the present article. First, robust priming was obtained for DIS and SIM letters in the naming task (Experiment 2), but priming was restricted to SIM letters in an alphabetic decision task (Experiment 1), a vowel-consonant categorization task (Experiment 3), and an identification task (Experiment 4). Second, robust priming was obtained for DIS and SIM words in all tasks that we used. These results are summarized in Table 7. Third, robust homophone priming was obtained between words (e.g., prime $=$ sail, target $=S A L E$ ) and between word/hetter pairs (e.g., prime $=$ sea, target $=C$ ) when the naming task was used in Experiments 5 and 6, but priming was greatly reduced between word homophones when the lexical decision task was used in Experiment 5.

These results pose two obvious puzzles: Why is DIS letter priming, as opposed to DIS word priming, restricted to the naming task? And why is homophone priming reduced in the lexical decision task compared with in the naming task? We suggest that both puzzles can readily be explained by adopting the position that DIS word priming is largely mediated by abstract orthographic codes, whereas DIS letter priming is mediated by phonological-articulatory codes. According to this account, DIS word priming should extend to all tasks, given that all tasks require the encoding of the orthographic properties of words, whereas DIS letter priming should largely be restricted to the naming task, given that this task selectively emphasizes the phonological and articulatory encoding of the target materials. The finding that both letter priming and word homophone priming are robust in the naming task supports this latter view. In the remainder of this section we attempt to characterize in more detail the representations that support letter and word priming.

\section{Abstract Orthographic Representations Support Word Priming}

In our view, the present results (a) support the claim that abstract orthographic codes often mediate priming for words and (b) challenge the view of a number of authors who argue that priming is largely mediated by phonological representations (e.g., Lukatela \& Turvey, 1994; Perfetti et al., 1988). Perhaps the strongest advocates of this position are Lukatela and Turvey (1994), who claimed that all word priming phenomena are phonological in nature regardless of the task requirements. They based their hypothesis on the cooccurrence of cross-case and homophone priming in their naming experiments. That is, whenever they observed priming between uppercase and lowercase primes and targets (e.g., prime $=S A I L$, target $=$ sail), they also observed priming between homophones (e.g., prime $=S A L E$, target $=$ sail $)$, which suggested that cross-case priming and homophone priming were mediated by the same representations-namely, phonological codes. They then extended this analysis and questioned the existence of abstract orthographic codes altogether. They wrote,

To the extent that the hypothesis of abstract graphemes is coupled with the absence of evidence for a true phonological

\footnotetext{
${ }^{6}$ It might be argued that our failure to obtain priming between phonologically similar letters was due to the fact that we included some prime/target letters that were only moderately similar phonologically, i.e., the pairs $k / Q$ and $a / R$. These pairs were included because we were restricted to the target letters $Q$ and $R$ given that they are homophonous with words. It should be noted that we have also run a priming experiment when the letters $p / B, t / D, c / Z$, and $j / G$ were included as primes and targets, and again, we found little evidence of priming ( $7 \mathrm{~ms}$ of priming, with slightly more errors in the repeated condition). And, as noted above, Arguin and Bub (1995) also reported the same null finding with a different set of letters.
} 
priming effect ... the present results suggest that this hypothesis is unwarranted. A better hypothesis, it seems, is that variants of a letter in English are functionally equivalent because they map to an invariant configuration of phonological features. (Lukatela \& Turvey, 1994, p. 347)

However, the combination of robust cross-case priming and null homophone priming for high-frequency targets in the lexical decision task (Experiment 5) contradicts their claim that cross-case priming and homophone priming always co-occur. Accordingly, our results support the existence of abstract orthographic codes and furthermore indicate that these codes support word priming. It is also worth mentioning that the existence of abstract orthographic word codes is supported by a number of different studies reported in the literature, including, among others, studies on the word superiority effect (Bowers, Bub, \& Arguin, 1996; McClelland, 1976), long-term priming phenomena (Bowers, 1996; Bowers \& Michita, 1998; Marsolek, Kosslyn, \& Squire, 1992), eye-tracking experiments (Rayner, McConkie, \& Zola, 1980), and matching experiments (Besner, Coltheart, \& Davelaar, 1984). We suggest that Lukatela and Turvey's (1994) reliance on the naming task led them to overemphasize the role of phonological codes in word processing.

Although orthographic codes play a critical role in DIS word priming in the lexical decision task, the robust homophone priming observed in the naming task (the present Experiments 5 and 6; also Lukatela \& Turvey, 1994) indicates that phonological-articulatory representations play a critical role when participants name the targets. Although the present experiments do not allow us to disentangle the relative contributions of phonological versus articulatory priming when the naming task is used, a number of findings suggest that the articulatory contribution is relatively small. The most relevant finding was reported by Lukatela and Turvey (1994), who assessed homophone priming for the same set of words that we included in our study. In their experiments, they included a condition in which targets were preceded by words that shared the same initial phonemes (e.g., TOLD/toad), which allowed a direct comparison between onset and homophone priming (they used the term quasi homographic to describe the condition in which words shared initial phonemes). They found a significant $12-\mathrm{ms}$ onset effect and a $29-\mathrm{ms}$ homophone priming effect when targets were low in frequency compared with primes, and a nonsignificant 6-ms onset and 27-ms homophone effect when targets were high in frequency compared with primes. Thus, these findings suggest that only a small proportion of the priming we obtained in the naming task should be attributed to articulatory effects.

In addition to the phonological-articulatory and abstract orthographic contributions to word priming, visually specific perceptual codes can also contribute to priming given that more priming was obtained for SIM than for DIS words in the perceptual identification task. It is important to emphasize, however, that SIM word priming and DIS word priming were equivalent in the lexical decision and nounverb categorization tasks, and in the identification task, the advantage of SIM words over DIS words was small (9\%) relative to the overall amount of SIM priming (43\%). Thus, the contribution of visually specific codes to word priming is relatively modest. The nature of these specific codes is taken up in more detail when the letter priming results are discussed.

One final issue regarding the representations that underlie the word priming results should be discussed here. We have been arguing that abstract orthographic representations are largely responsible for the obtained priming effects (at least in non-naming tasks), but we have not discussed the nature of these orthographic codes. One possibility is that sublexical orthographic representations mediate priming-such as abstract, bigram, or trigram codes-consistent with the hypothesis advanced by Humphreys and colleagues (Humphreys, Besner, \& Quinlan, 1988; Humphreys et al., 1990). In support of this view are the various reports that priming extends to pseudowords in naming and perceptual identification tasks (e.g., Humphreys et al., 1990; Masson, 1991), and this approach is congruent with theories that deny the existence of lexical-orthographic knowledge (e.g., Seidenberg \& McClelland, 1989). Another possibility, however, is that lexical-orthographic representations mediate priming, which is consistent with the view of Forster and his colleagues. In support of this latter view, priming is often restricted to words when the lexical decision task is used (e.g., Forster \& Davis, 1984), and furthermore, this approach is congruent with the view that reading involves accessing lexical-orthographic codes (e.g., Forster \& Davis, 1991; McClelland \& Rumelhart, 1981). Of course, a third possibility is that word priming effects reflect a combination of both lexical and sublexical factors.

A recent study by Bowers, Arguin, and Bub (1996) suggests that sublexical codes can in fact support priming. The study assessed masked priming for words and pseudowords in a patient, I.H., who reads in a letter-by-letter fashion; that is, I.H. reads very slowly, and his reading times are a linear function of word length, with an approximately 500-ms increase in reading RTs with each additional letter. Despite his slow reading, I.H. showed robust priming in the naming task for both words and pseudowords when primes were displayed for $100 \mathrm{~ms}$. Furthermore, he failed to show pseudoword priming when primes and targets differed only in the fourth letter position (e.g., tern/TERB). This latter finding indicates that the pseudoword priming was not the product of an onset effect. Thus, the robust repetition priming for pseudowords must have been mediated by the activation of sublexical codes-either orthographic or phonological. Given that I.H. has slow access to phonological knowledge, as revealed by his failure to show masked homophone priming in the naming task (Arguin, Bub, \& Bowers, 1998), it seems likely that sublexical orthographic codes were responsible, consistent with the view of Humphreys et al. (1990). But, clearly, these findings are consistent with the view that lexical representations also contribute to masked priming phenomena.

Finally, we would like to conclude this section by briefly noting some of the more general implications of the homophone priming results reported in Experiment 5. A number of authors have argued that access to phonology is 
virtually always prior to, and even necessary for, visual word recognition during reading (e.g., Lukatela \& Turvey, 1994; Perfetti et al., 1988; Van Orden, 1987). The key evidence presented in support of this conclusion comes from studies that reported a high proportion of homophone errors in semantic categorization tasks (e.g., participants mistakenly categorized rows as a flower; Van Orden, 1987) and studies that reported masked priming between homophones (e.g., Perfetti \& Bell, 1991; Perfetti et al., 1988). However, in contrast to this position, Jared, McRae, and Seidenberg (1990) reported that homophone errors in the semantic categorization task were restricted to low-frequency homophone targets, which suggests that although phonology can play an important role in word identification, its role is more pronounced for low-frequency words (See also V. Coltheart, Patterson, \& Leahy, 1994, for further restrictions regarding the conditions in which homophone errors are made.) Our findings provide similar constraints regarding the conditions in which phonological codes are used in word-processing tasks given that homophone priming in the lexical decision task was restricted to the low-frequency targets. Thus, we would suggest that the strong conclusion that phonology is virtually always necessary for visual word identification is unwarranted (also see, among others, Baluch \& Besner, 1991; Besner, Twilley, McCann, \& Seergobin, 1990; Tabossi \& Laghi, 1992; Waters \& Seidenberg, 1985). Note that it may well be the case that phonological codes are computed automatically following the visual presentation of a word, but they may not always be used for identification (for a discussion of the distinction between whether phonology is computed or used, see Besner, Dennis, \& Davelaar, 1985).

\section{Phonological Codes and Articulatory Processes Mediate Letter Priming}

We believe DIS letter priming, in sharp contrast to word priming, is exclusively mediated by phonological-articulatory processes. This conclusion is based on (a) the equivalent homophone and cross-case letter priming we observed (Experiment 6) and (b) the finding that DIS letter priming was obtained in the naming task (Experiment 2) but not in tasks that did not require participants to phonologically encode and articulate letters (Experiments 1, 3, and 4). In addition, converging evidence for this position can be found in a number of related studies. For example, Bowers et al. (1996) reported that I.H., the letter-by-letter patient, failed to show priming for DIS letters when primes were displayed for $100 \mathrm{~ms}$ in the naming task, even though this same prime duration supported word priming in this patient. A plausible interpretation of this finding is that I.H. was able to gain fast access to orthographic word knowledge but that his letter-byletter reading prevented him from gaining fast access to phonological-articulatory processes, which in turn selectively impaired his priming for letters.

As in the case of words, it will be important to determine the relative role that phonological and articulatory effects play in DIS letter priming. That is, at least some of the observed priming may reflect the fact that participants prepared to articulate the prime letter prior to the encoding of the target, which facilitated target naming when prime and target shared the same name and inhibited target naming otherwise. However, the relative role of these factors is impossible to determine at present.

Although DIS letter priming was restricted to the naming task, there was a consistent trend for SIM letter priming in all tasks, with substantial priming in the identification task. Thus, it appears that perceptually specific representations can also support letter priming, as was the case with words in the identification task. At present, however, we can only speculate about the nature of these representations. Presumably, these codes are not low-level (iconic) visual traces of the prime because lower- and uppercase SIM letters differ in size, among other attributes. Instead, these codes must map together items that share critical (unspecified) visual attributes. One possibility is that these codes are visually specific letter tokens that map onto abstract letter representations, which is consistent with the view of Arguin and Bub (1995). So in this view, SIM priming is mediated by representations within the orthographic system itself. Another possibility is that these representations lie outside the orthographic system altogether. For example, the SIM priming may be mediated by representations in the right hemisphere that code visual information in a more specific format, whereas DIS priming is mediated by abstract representations within the orthographic system in the left hemisphere (Marsolek, 1995; Marsolek et al., 1992). Whatever the case, the results clearly indicate the importance of considering the perceptual attributes of letters and words when using priming paradigms.

\section{General Implications Regarding the Orthographic System}

Our failure to obtain DIS letter priming in non-naming tasks may have implications regarding the representational status of letters; that is, the results might be taken to indicate that abstract letter codes do not exist. In this view, orthographic letter codes are case specific, and these codes would presumably connect to abstract word or sublexical representations, providing a basis for abstract orthographic word priming in the absence of letter priming. Although we cannot unequivocally rule out this hypothesis, we are reluctant to advocate this position given that some findings directly support the existence of abstract letter codes (not inferred from word or pseudoword results). For example, some patients with developmental or acquired reading disorders have difficulties naming individual letters but nevertheless have no problems matching upper- and lowercase DIS letters (e.g., M. Coltheart, 1981; Rynard \& Besner, 1987). It is plausible to assume that in order to correctly perform the matching task, these individuals access abstract orthographic letter codes (for additional evidence in direct support of abstract letter codes, see Besner \& Jolicoeur, 1998, and Mozer, 1989; for another interpretation of crosscase letter matching, see Boles \& Eveland, 1983). It must be acknowledged, however, that the majority of research evidence taken as support for abstract letter codes has been 
obtained using word and pseudoword materials, and accordingly, additional research on this issue is needed.

Alternatively, the absence of DIS priming in non-naming tasks may reflect the specific processes involved in reading single letters, in which case the results do not speak to representational issues. In this, our preferred view, the absence of DIS letter priming reflects the short-lasting activation of abstract letter codes following the presentation of the prime, which is due either to a fast decay rate of letter activation or to an active suppression of this activation when new letter information (the target) arrives. In both cases, the prior encoding of the prime would not facilitate the processing of the target because the letter activation would be at baseline levels again when the target was encoded.

In order to account for the overall pattern of letter and word priming results, we would have to assume that the activation of lexical-orthographic knowledge is more persistent than the activation of single-letter codes as well as assume that the decay rate of phonological codes is relatively slow (or the activation of these codes is not suppressed by new information). In this scenario, word priming would indeed extend to all tasks and would reflect the activation of abstract orthographic codes, and phonological codes would support DIS letter and homophone (and DIS word) priming whenever the naming task was used.

Of course, we readily admit that it is speculative to suggest that the activation of orthographic letter codes is less persistent than the activation of orthographic word codes or phonological letter codes, and additional work is required before any firm conclusions can be drawn. Still, the present results highlight the possibility that the activation time courses for abstract orthographic letter and word representations, as well as for phonological letter codes, are different. Computational accounts of letter and word processing have typically assumed, for the sake of parsimony, that the activation properties of orthographic letter and word codes are the same (Jacobs \& Grainger, 1992; McClelland \& Rumelhart, 1981). The present findings should at least raise concerns about this assumption.

In summary, we have provided strong evidence that orthographic representations support priming for words, whereas phonological-articulatory codes support priming for single letters. We suggest that both abstract letter codes and abstract word codes exist in the orthographic system but that for some reason, only orthographic word codes support priming.

\section{References}

Adams, M. J. (1979). Models of word recognition. Cognitive Psychology, 11, 133-176.

Allen, P. A., Wallace, B., \& Weber, T. A. (1995). Influence of case type, word frequency, and exposure duration on visual word recognition. Journal of Experimental Psychology: Human Perception and Performance, 21, 914-934.

Arguin, M., \& Bub, D. (1995). Priming and response selection processes in letter classification and identification tasks. Journal of Experimental Psychology: Human Perception and Performance, 21, 1199-1219.

Arguin, M., Bub, D., \& Bowers, J. S. (1998). Extent and limits of covert lexical activation in letter-by-letter reading. Cognitive Neuropsychology, 15, 53-92.

Baluch, B., \& Besner, D. (1991). Visual word recognition: Evidence for strategic control of lexical and nonlexical routines in oral reading. Journal of Experimental Psychology: Learning, Memory, and Cognition, 17, 644-652.

Besner, D., Coltheart, M., \& Davelaar, E. (1984). Basic processes in reading: Computation of abstract letter identities. Canadian Journal of Psychology, 38, 126-134.

Besner, D., Dennis, I., \& Davelaar, E. (1985). Reading without phonology? Quarterly Journal of Experimental Psychology: Human Experimental Psychology, 37A, 477-492.

Besner, D., \& Johnston, J. C. (1989). Reading and the mental lexicon: On the uptake of visual information. In W. MarslenWilson (Ed.), Lexical representations and processes (pp. 291316). Cambridge, MA: MIT Press.

Besner, D., \& Jolicoeur, P. (1998). Basic processes in reading: Cross-case letter matching without phonology. Manuscript submitted for publication.

Besner, D., Twilley, L., McCann, R. S., \& Seergobin, K. (1990). On the association between connectionism and data: Are a few words necessary? Psychological Review, 97, 432-446.

Boles, D. B., \& Clifford, J. E. (1989). An upper- and lower case alphabetic similarity matrix, with derived generation similarity values. Behavior Research Methods, Instruments, \& Computers, $12,597-586$

Boles, D. B., \& Eveland, D. C. (1983). Visual and phonetic codes and the process of generation in letter matching. Journal of Experimental Psychology: Human Perception and Performance, 9, 657-674.

Bowers, J. S. (1996). Different perceptual codes support word and pseudoword priming: Was Morton right all along? Journal of Experimental Psychology: Learning, Memory, and Cognition, 22, 1336-1353.

Bowers, J. S., Arguin, M., \& Bub, D. (1996). Fast and specific access to orthographic knowledge in a case of letter-by-letter surface alexia. Cognitive Neuropsychology, 13, 525-567.

Bowers, J. S., Bub, D., \& Arguin, M. (1996). A characterization of the word superiority effect in a case of letter-by-letter surface alexia. Cognitive Neuropsychology, 13, 415-441.

Bowers, J. S., \& Michita, Y. (1998). An investigation into the structure and acquisition of orthographic knowledge: Evidence from cross-script Kanji-Hiragana priming. Psychonomic Bulletin \& Review, 5, 259-264.

Coltheart, M. (1981). Disorders of reading and their implications for models of normal reading. Visible Language, 3, 245-286.

Coltheart, V., Patterson, K., \& Leahy, J. (1994). When a ROWS is a ROSE: Phonological effects in written word comprehension. Quarterly Journal of Experimental Psychology: Human Experimental Psychology, 47A, 917-955.

Davelaar, E., Coltheart, M., Besner, D., \& Jonasson, J. T. (1978). Phonological recoding and lexical access. Memory \& Cognition. 6, 391-402.

Davis, C., \& Forster, K. I. (1994). Masked orthographic priming: The effect of prime-target legibility. Quarterly Journal of Experimental Psychology: Human Experimental Psychology, 47A, 673-697.

Evett, L. J., \& Humphreys, G. W. (1981). The use of abstract graphemic information in lexical access. Quarterly Journal of Experimental Psychology: Human Experimental Psychology, 33A, 325-350.

Ferrand, L., \& Grainger, J. (1992). Phonology and orthography in visual word recognition: Evidence from masked nonword priming. Quarterly Journal of Experimental Psychology: Human Experimental Psychology, 45A, 353-372. 
Ferrand, L., \& Grainger, J. (1993). The time-course of orthographic and phonological code activation in the early phases of visual word recognition. Bulletin of the Psychonomic Society, 3I, 119-122.

Ferrand, L., \& Grainger, J. (1994). Effects of orthography are independent of phonology in masked form priming. Quarterly Journal of Experimental Psychology: Human Experimental Psychology, 47A, 365-382.

Forster, K. I. (1992). Lexical effects in masked form-priming. Paper presented at the 33rd annual meeting of the Psychonomic Society, St. Louis, MO.

Forster, K. I., \& Davis, C. (1984). Repetition priming and frequency attenuation in lexical access. Journal of Experimental Psychology: Learning, Memory, and Cognition, 10, 680-698.

Forster, K. I., \& Davis, C. (1991). The density constraint on form-priming in the naming task: Interference effects from a masked prime. Joumal of Memory and Language, 30, 1-25.

Grainger, J., \& Ferrand, L. (1994). Phonology and orthography in visual word recognition: Effects of masked homophone primes. Journal of Memory and Language, 33, 218-233.

Henderson, L., Wallis, J., \& Knight, D. (1984). Morphemic structure and lexical access. In H. Bouma \& D. Bouhuis (Eds.), Attention \& performance $X$. London: Erlbaum.

Humphreys, G. W., Besner, D., \& Quinlan, P. T. (1988). Event perception and the word repetition effect. Journal of Experimental Psychology: General, 117, 51-67.

Humphreys, G. W., Evett, L. J., \& Quinlan, P. T. (1990). Orthographic processing in visual word identification. Cognitive Psychology, 22, 517-560.

Humphreys, G. W., Evett, L. J., \& Taylor, D. E. (1982). Automatic phonological priming in visual word recognition. Memory \& Cognition, 10, 576-590.

Jacobs, A. M., \& Grainger, J. (1991). Automatic letter priming in an alphabetic decision task. Perception \& Psychophysics, 47, 43-52.

Jacobs, A. M., \& Grainger, J. (1992). Testing a semi-stochastic variant of the interactive activation model in different word recognition experiments. Journal of Experimental Psychology: Human Perception and Performance, 18, 1174-1188.

Jacobs, A. M., Grainger, J., \& Ferrand, L. (1995). The incremental priming technique: A method for determining within-condition priming effects. Perception \& Psychophysics, 57, 1101-1110.

Jared, D., McRae, K., \& Seidenberg, M. S. (1990). The basis of consistency effects in word naming. Journal of Memory and Language, 29, 687-715.

Kuçera, H., \& Francis, W. N. (1967). Computational analysis of present-day American English. Providence, RI: Brown University Press.

Lukatela, G., \& Turvey, M. T. (1994). Visual lexical access is initially phonological: 2 . Evidence from phonological priming by homophones and pseudohomophones. Journal of Experimental Psychology: General, 123, 331-353.

Marsolek, C. J. (1995). Abstract visual-form representations in the left cerebral hemisphere. Journal of Experimental Psychology: Human Perception and Performance, 21, 375-386.

Marsolek, C. J., Kosslyn, S. M., \& Squire, L. R. (1992). Formspecific visual priming in the right cerebral hemisphere. Journal of Experimental Psychology: Learning, Memory, and Cognition, 18, 492-508.

Masson, M. E. J. (1991). Word repetition as the eyes see it. Paper presented at the 32nd annual meeting of the Psychonomic Society, San Francisco.

McClelland, J. L. (1976). Preliminary letter identification in the perception of words and nonwords. Journal of Experimental Psychology: Human Perception and Performance, 3, 80-91.

McClelland, J. L., \& Rumelhart, D. E. (1981). An interactive activation model of context effects in letter perception: Part 1. An account of basic findings. Psychological Review, 88, 375407.

Meyer, D. E., \& Schvaneveldt, R. W. (1971). Facilitation in recognizing pairs of words: Evidence of a dependence between retrieval operations. Journal of Experimental Psychology, 91, 227-234.

Mozer, M. (1989). Types and tokens in visual letter perception. Journal of Experimental Psychology: Human Perception and Performance, 15, 287-303.

Perfetti, C. A., \& Bell, L. (1991). Phonemic activation during the first $40 \mathrm{~ms}$ of word identification: Evidence from backward masking and priming. Journal of Memory and Language, 30 , 473-485.

Perfetti, C. A., Bell, L. C., \& Delaney, S. (1988). Automatic (prelexical) phonetic activation in silent word reading: Evidence from backward masking. Journal of Memory and Language, 27, 59-70.

Rayner, K., McConkie, G. W., \& Zola, D. (1980). Integrating information across eye movements. Cognitive Psychology, 12, 206-226.

Reicher, G. M. (1969). Perceptual recognition as a function of meaningfulness of stimulus material. Journal of Experimental Psychology, 81, 274-280.

Rynard, D., \& Besner, D. (1987). Basic processes in reading: On the development of cross-case letter matching without reference to phonology. Bulletin of the Psychonomic Society, 25, 361-368.

Seidenberg, M. S., \& McClelland, J. L. (1989). A distributed, developmental model of word recognition and naming. Psychological Review, 96, 523-568.

Tabossi, P., \& Laghi, L. (1992). Semantic priming in the pronunciation of words in two writing systems: Italian and English. Memory \& Cognition, 20, 315-328.

Van Orden, G. C. (1987). A ROWS is a ROSE: Spelling, sound and reading. Memory \& Cognition, 15, 181-198.

Verstaen, A., Humphreys, G. W., Olson, A., \& D'Ydewalle, G. (1996). Are phonemic effects in backward masking evidence for automatic prelexical phonemic activation in visual word recognition? Journal of Memory and Language, 34, 335-356.

Waters, G. S., \& Seidenberg, M. (1985). Spelling-sound effects in reading: Time course and decision criteria. Memory \& Cognition, 13, 557-572.

Received March 1, 1996

Revision received September 8, 1997

Accepted October 20, 1997 